\title{
Sustainability of exploited marine ecosystems through protected areas: A viability model and a coral reef case study
}

\author{
L. Doyen ${ }^{a, *}$, M. De Lara $^{b}$, J. Ferraris ${ }^{c}$, D. Pelletier ${ }^{d}$
}

\author{
${ }^{a}$ CNRS, CERSP, Dpt Ecologie et Gestion de la Biodiversité, MNHN, 55 rue Buffon, 75005 Paris, France \\ ${ }^{\mathrm{b}}$ Cermics, ENPC, 6 et 8 avenue B. Pascal, 77455 Marne la Vallée Cedex 2, France \\ ${ }^{c}$ UR 128 CoReUs, IRD, Université de Perpignan, 66860 Perpignan, France. \\ ${ }^{\mathrm{d}}$ Département EMH, IFREMER BP 21105, 44311 Nantes Cedex 3, France \\ *: Corresponding author : Luc Doyen : lucdoyen@mnhn.fr
}

\begin{abstract}
:
Over-exploitation of marine resources remains a problem worldwide. Many works advocate for the use of marine reserves as a central element of future stock management in a sustainable perspective. In the present paper, we address the influence of protected areas upon fisheries sustainability within an eco-systemic framework through a dynamic bio-economic model integrating atrophic web, catches and environmental uncertainties. The model is spatially implicit. The evaluation of the ecosystem is designed through the respect along time of constraints of both conservation and guaranteed captures. Using the mathematical concept of invariance kernel in a stochastic context, we define different MPA effects according to biodiversity, catches or mixed points of view. Numerical simulations inspired from data of Abor'e coral reef reserve in New Caledonia illustrate the main concepts. In this case, it is pointed out how MPA conservation effect is not necessarily conflicting with MPA catches effect. It is shown that such a co-viability requires medium exploitation rate. Moreover, the climatic changes represented by rise in cyclonic events seem to reinforce these assertions.
\end{abstract}

Keywords: Marine ecosystems, renewable resource, fisheries management, marine protected area, co-viability, invariance analysis. 


\section{Introduction}

Marine ecosystems and corresponding exploited resources remain exposed to considerable anthropogenic pressure worldwide despite the endeavors for better regulations in terms of economic or control instruments and measures of stocks and catches. In this context, marine reserves have been advocated as a central element for sustainable management of ecosystems and biodiversity conservation, in particular in coastal areas.

Marine reserves were first envisaged as conservation tools and natural laboratories, and therefore the majority of existing reserves are small areas. By the early 1990s, and facing a generalized overexploitation of fish resources, marine reserves have been more and more considered as tools for restoring fisheries sustainability. In this respect, prescriptions have been publicized as to the need for larger reserves. Although there has been some controversy about the relevance of marine reserves and Marine Protected Areas (MPA) in general for fisheries management (Hilborn et al. , 2005), a number of benefits are expected from the establishment of marine reserves. These main expected effects are increased abundances of spawning stocks and recruitment in areas surrounding the reserve through spillover of recruited stages and larval dispersion, and increase in mean fish size due to a lesser exploitation level. In addition, expected benefits for biodiversity conservation are likely to enhance resource sustainability, enhanced ecosystem resilience (Grafton et al. , 2005b), protection of essential habitats. Marine reserves have also been hypothesized to provide a bet-hedging management strategy against management failures (Lauck et al. , 1998). Hence, there are positive clues indicating the effectiveness of marine reserves for fisheries. Regarding this, a review of the bioeconomics literature on MPA can be found in (Grafton et al. , 2005a). Despite the positive clues, the payoffs of MPA for fisheries are far from being demonstrated from soundly designed empirical experiments (Russ, 2002). Therefore, drastic prescriptions of closing large parts of fisheries areas without guaranteed benefits for fishers are bound to raise a large opposition and may even bear deleterious consequences for the overall credibility of marine reserves (Agardy et al. , 2003). A particular issue concerns the consequences of changes in trophic interactions following the establishment of marine reserves, the so-called trophic cascades (Pinnegar et al. , 2000). Although many modeling studies have investigated fisheries benefits of marine reserve (Pelletier \& Mahévas, 2005; Sanchirico \& Wilen, 2001; Sanchirico, 2005; Smith \& Wilen, 2003), few of them have addressed consequences of trophic cascades to the exception of Beatie et al. (2002), Boncoeur et al. (2002) or Shin (2001). Many of these studies rely on strong equilibrium assumptions. Published studies do not provide a diagnostic about the sustainability of observed changes for the whole ecosystem and particularly for depending resources. Very few studies have attempted to evaluate the economic sustainability of fisheries after reserve establishment 
(Beatie et al. , 2002). An important paper for the economic sustainability of fisheries after reserve establishment is Grafton et al. (2005b) that addresses the resilience effects ("à la Pimm") of a reserve in the presence of negative shocks. The paper shows that a reserve yields a better catch than without a reserve in the presence of negative shocks by allowing for spillovers to the harvested area and faster recovery following the disturbance.

Several modeling approaches may be used to cope with fisheries and ecosystem sustainability. This stems from the fact that the definition of sustainability remains controversial. Hence Charles (2001) provides definitions of several sorts of fisheries sustainability including ecological, economic, etc. Steadystate approaches as MSY rely on equilibrium assumptions, and therefore may not appear appropriate for a proper account of uncertainty (Conrad, 1999). Optimal control theory has been used to define fisheries management strategies (Clark, 1990). Although it offers a more dynamic perspective, undesirable outcomes of such an optimality approach reduces its applicability in terms of sustainability. One problem is resource extinction: it could be optimal to exhaust the resource; Another difficulty displayed by optimal control relies on intergenerational equity issue: optimal catches may be zero at the beginning or the end of the period at stake depending on the preferences for future or present induced by the discount rate (Heal, 1998). Moreover, optimal control is not easy to apply in a multi-criteria context. Furthermore, as in Beatie et al. (2002), such an approach generally introduces existence prices for biodiversity or species and this monetary approach for conservation can be criticized.

In the present paper, we do not look for optimal trajectories for the coevolution of resources, but rather for desirable paths that achieve fisheries sustainability or prevent catastrophic developments. These paths are determined using the viability (Aubin, 1991) or invariance approach (Clarke et al. , 1995). Such invariance or viability approach focuses on inter-temporal feasible trajectories. It first requires the identification of a set of constraints that encompasses the desirable states of the ecosystem, corresponding to a healthy or safe system or the effectiveness of the system. The approach analyzes the conditions which allow these constraints to be fulfilled at any time, including both present and future. We refer for instance to Béné \& Doyen (2000), Béné et al. (2001), Eisenack et al. (2006), Rapaport et al. (2006), DeLara et al. (2007), Martinet et al. (in press), Tichit et al. (in press) for applied works coping with renewable resources management. The paper Cury et al. (2005) advocates for the use of viability approach to integrate ecosystem considerations for fisheries management. More specifically, Doyen \& Bene (2003) focus on MPA effects using the concept of invariance kernel. From the ecological viewpoint, the so-called population viability analysis (PVA) (Morris \& Doak, 2003) and conservation biology has concerns close to viable control approach by focusing to extinction process, situations and regulations in an uncertain (stochastic) framework. The Tolerable Windows Approach (TWA) proposes a 
similar framework on climatic change issues (Bruckner et al. , 1999). In the environmental context, viability may allow for the satisfaction of both economic and environmental constraints. In this sense, it is a multi-criteria approach. Moreover, since the viability constraints are the same at any moment and the term horizon is infinite, an intergenerational equity feature is naturally integrated within this framework. As emphasized in Martinet \& Doyen (2007), this approach is deeply close to the maximin approach exposed by Rawl's or Solow (Heal, 1998).

In the present paper, we use the invariance approach to study the viability of an exploited food web, and the interest of establishing a marine reserve for ensuring its sustainability. In particular, we discuss how to combine catches and ecosystem requirements in a perspective of a multi-criteria analysis. More specifically, we address the following questions : (i) How to define sustainability in terms of simultaneous objectives of catches and conservation in the presence of a marine reserve? (ii) How to define a reserve effect in this context? (iii) Is there a reserve size that especially promotes catch or direct use of the ecosystem?

The analysis is applied to a simplified coral reef ecosystem. Coral reef systems have a widespread distribution over the world and they are among the most diverse ecosystems. They support many small-scale fisheries, and provide economic and environmental services to millions of people as shoreline protection, recreation and tourism, and sources of food, pharmaceuticals, jobs, and revenues. They are threatened in several ways: coral bleaching presumably due to global changes, overfishing and destructive fishing practices (Connell et al. , 1997; Cesar, 2000; Pandolfi, 2003; Hughes, 2003; Bellwood et al. , 2004). The MPA of South-West lagoon in New Caledonia (South Pacific) with the Aboré reef reserve example offers an interesting case study depicted in Amand et al. (2003) or Ferraris et al. (2005). The trophic web is dependent on the state of the coral reef since it serves as a refuge for small prey and a habitat for many species. In this area, corals suffer from cyclonic events, which might occur more frequently in relation with global climate changes (IPCC, 2001). The sustainability of this ecosystem thus raises several interesting and interrelated issues : fisheries sustainability, conservation of fish diversity and protection of coral habitat. The Aboré reef is nowadays totally closed after an unsuccessful attempt of rotating reserve with an opening of the MPA to fishing in 1993 following three years of closure. We study the conditions under which fishing may be authorized again in a limited part of the reef through the size of a marine reserve.

The paper is organized as follows. In section 2, we present a generic model describing population dynamics and environment evolution. Then the viability constraints are identified taking into account both catch and conservation requirements. Using the mathematical concept of invariance kernel, we intro- 
duce distinct quantitative reserve effects. In section 3, the approach is applied to the Aboré reef reserve. Section 4 concludes. Technical details related to parameter identification and data for the example are reported in an appendix.

\section{The general discrete time bioeconomic model}

\subsection{The discrete time dynamics}

The trophic food web and the habitat: We consider an ecosystem composed of $n$ natural populations described through their density or biomass $x_{i}(t)$ together with an habitat or environment whose state at time $t$ is denoted by $y(t)=\left(y_{1}(t), \ldots, y_{m}(t)\right)$. These populations and this habitat interact through the dynamics:

$$
\left\{\begin{array}{l}
x_{i}(t+1)=x_{i}(t) f_{i}(x(t), y(t), \omega(t)), \quad t=0,1, \ldots, T \\
y_{j}(t+1)=g_{j}(x(t), y(t), \omega(t)),
\end{array}\right.
$$

where it is assumed that

- The per capita growth $f_{i}(x, y, \omega)$ may depend on the overall population density $x(t)=\left(x_{1}(t), \ldots, x_{n}(t)\right)$ and on the habitat $y(t)$ along with some uncertain biological parameters related to the state of the world $\omega(t)$. This per capita growth of each species $f_{i}$ is positive in the sense that ${ }^{1}$

$$
f_{i}(x, y, \omega) \geq 0, \forall x \in \mathbb{R}_{+}^{n}, \forall y \in \mathbb{R}_{+}^{m}, \forall \omega, \forall i \in\{1, . ., n\} .
$$

- The state of world $\omega(t)$ evolves within a domain of possible scenarios $\Omega$ :

$$
\omega(.)=(\omega(1), \ldots, \omega(T)) \in \Omega .
$$

The dependence of some parameters upon the uncertainty $\omega(t)$ accounts for climatic or global change scenarios.

- The $j$ component of habitat $y(t)$ only changes through the growth function $g_{j}$ that is a function of the environmental uncertainty $\omega(t)$. The dynamics $g_{j}$ are assumed to be positive.

$\overline{1}$ Note that under equation (1), any population that reaches a zero density definitively collapses, so that zero is an absorbing state:

$$
x_{i}(t)=0 \Longrightarrow x_{i}(s)=0, \forall s \geq t
$$


Typical instances of such multi-species dynamics and trophic web are given by resource based dynamics or Lokta-Volterra and prey-predator relationship such as

$$
f_{i}(x, y)=a_{i}(y)+\sum_{j} b_{i j}(y) x_{j}
$$

with $b_{i j}=-\mu b_{j i}$ for $j \neq i$.

Equation (1) may be written in a vectorial form:

$$
\left\{\begin{array}{l}
x(t+1)=F(x(t), y(t), \omega(t)), \\
y(t+1)=G(x(t), y(t), \omega(t))
\end{array}\right\}
$$

where $F_{i}(x, y, \omega)=x_{i} f_{i}(x, y, \omega)$ and $G_{j}(x, y, \omega)=g_{j}(x, y, \omega)$.

The exploited dynamics: Now we consider that, within the ecosystem, each resource $x_{i}($.$) can be harvested through a fishing effort e(\omega(t))$ that is possibly subject to uncertainty. Corresponding catches $c_{i}(t)$ write:

$$
c_{i}(t)=H_{i}\left(e(\omega(t)), x_{i}(t)\right)
$$

where we assume that

$$
H_{i}(0, x)=H_{i}(e, 0)=0, \frac{\partial H_{i}}{\partial e}(x, e) \geq 0, \frac{\partial H_{i}}{\partial x_{i}}(x, e) \geq 0 .
$$

An example of harvest functions $H$ is given by the linear Gordon-Schaefer case $H(e, x)=q e x$, but other functions could be used such as predationtype functional responses or Cobb-Douglas production functions of the type $H(u, x)=q e^{\alpha} x^{\beta}$. Assuming that harvest $c_{i}(t)$ occurs at the beginning of the time step, population dynamics for any given species $i$ becomes:

$$
x_{i}(t+1)=\left(x_{i}(t)-c_{i}(t)\right) f_{i}(x(t)-c(t), \omega(t)) .
$$

For sake of simplicity, it is assumed that catch and exploitation do not alter habitat $y(t)$. A straightforward constraint is derived from harvesting as catch cannot exceed population state:

$$
0 \leq c_{i}(t) \leq x_{i}(t)
$$

The exploited dynamics in the presence of a protected area: Because the dynamics is not spatially explicit and we are mainly interested in reserve 
size, the existence of a reserve is characterized through a fixed proportion $A \in[0,1]$ of the ecosystem that may be harvested. This approach is similar to that of Lauck et al. (1998). Consequently, the catch is given by

$$
c(t)=H(e(\omega(t)), A x(t))
$$

and the dynamics reads as follows

$$
\left\{\begin{array}{l}
x(t+1)=F(x(t)-H(e(\omega(t)), A x(t)), y(t), \omega(t))), \\
y(t+1)=G(x(t), y(t), \omega(t)) .
\end{array}\right.
$$

\subsection{The viability constraints}

The assessment for the sustainability of the ecosystem under exploitation is here considered through state constraints. In this sense, it corresponds to a viability or invariance approach.

A direct use value: The ecosystem provides direct use values through possible catches and production value. We use a utility framework to take into account such economic value. At each time step, species contributes to the overall production $U\left(c_{1}(t), \ldots, c_{n}(t)\right)$ and guaranteed utility $U^{\mathrm{b}}>0$ is required as follows :

$$
U\left(c_{1}(t), \ldots, c_{n}(t)\right) \geq U^{b}, \quad t=0,1, \ldots, T
$$

We only assume that the function $U$ is increasing with respect to each component $c_{i}$ and vanishes at $c=0$ namely

$$
U(0)=0 ; \frac{\partial U}{\partial c_{i}}(c) \geq 0
$$

The utility function may be modelled in several ways as

- Additive form $U(c)=\sum_{i} p_{i} c_{i}$ : harvests from each species have complementary values but are not essential: some catches $c_{i}$ may vanish without imposing zero utility.

- Cobb Douglass production form $U(c)=\prod_{i} c_{i}^{\lambda_{i}}$ where the species have substitutable values and are essential: zero catch on only one species annihilates the whole utility. 
An implicit conservation constraint: Combining the scarcity constraint (5), the increasing property of $U$ along with guaranteed utility requirement

(7), we derive a conservation constraint for the exploited resources

$$
U\left(x_{1}(t), \ldots, x_{n}(t)\right) \geq U\left(c_{1}(t), \ldots, c_{n}(t)\right) \geq U^{b}
$$

As $U$ cancels at 0 , then at least one population of concern in the direct utility function should not go extinct in the sense that

$$
\exists i \text { such that } x_{i}(t)>0 \text {. }
$$

An explicit conservation constraint: The existence of at least one exploited population is guaranteed through the implicit conservation constraint (9) above. However, stronger conservation constraints may be imposed by considering explicit population viability constraints. At this stage, a possible option is to introduce a biodiversity indicator $B(x)$. We aim at ensuring a minimal biodiversity index $B_{b}$

$$
B(x(t)) \geq B_{\mathrm{b}}, \quad t=0,1, \ldots, T .
$$

Examples of such biodiversity value $B(x)$ are given by

- Species richness: $B(x)=\sum_{i} \mathbf{1}_{R_{*}^{+}}\left(x_{i}\right)$ where $\mathbf{1}_{R_{*}^{+}}$stands for the characteristic of the strictly positive real line ${ }^{2}$.

- Strong conservation: $B(x)=\min _{i}\left(x_{i}\right)$. In this last case, any strictly positive guaranteed threshold $B_{\mathrm{b}}>0$ ensures that every species is not extinct. This a strong version of sustainability and preservation of biodiversity since we do require to conserve every resource systematically.

\section{Analysis of the effectiveness of reserve management}

We are interested in studying the sustainability of the ecosystem described by dynamics (6), given environmental uncertainties $\omega(t)$ and as a function of the size $1-A$ of the reserve. The ecosystem is said to be sustainable or viable if conservation constraints (10) as well as the guaranteed use value (7) provided by the ecosystem can be satisfied along time.

$\overline{2}$ The characteristic function of positive reals is

$$
\mathbf{1}_{R_{*}^{+}}= \begin{cases}1 & \text { if } x>0 \\ 0 & \text { if } x \leq 0\end{cases}
$$




\subsection{Robust indicators of global sustainability for the ecosystem}

A measure of such a sustainability is performed by the mathematical concept of invariance kernel described below. The objective here is to identify the initial levels of resource and habitat together with protected area rate that yields viable paths irrespective of the uncertain sequential scenario. In a formal way, this requires to compute the set of initial levels of population states $x(0)=\left(x_{1}(0), x_{2}(0), \ldots, x_{n}(0)\right)$ and habitat $y(0)=\left(y_{1}(0), y_{2}(0), \ldots, y_{m}(0)\right)$ such that given the possible scenarii $\omega()=.(\omega(0), \omega(1), \ldots, \omega(t), \ldots, \omega(T)) \in$ $\Omega$, the ecosystem remains viable with a large probability namely at a given confident rate $\beta$ close to one. Viable means here that the population densities $x_{i}(t)$ provides a guaranteed utility $U^{b}$ through catch $c_{i}(t)$ while maintaining populations $x_{i}(t)$ at some given level of biodiversity $B_{b}$ for a period of time $T$. This set of initial levels for population and habitat density $\left(x_{0}, y_{0}\right)$ is called the invariance kernel associated with the ecosystem dynamics (6), biodiversity (10) and catch (7) constraints. Because we consider conservation and exploitation under environmental uncertainty, this invariance kernel can be considered as a indicator of the robust sustainability ${ }^{3}$ of the exploited ecosystem.

To achieve this, let us consider a probability $\mathbb{P}$ on scenarios $\Omega$, a confidence rate $\beta \in] 0,1]$ together with a time horizon $T>0$. The indicator of sustainability at confidence rate $\beta$ is given by the invariance kernel $\operatorname{Sust}_{\beta}\left(A, U_{b}, B_{b}\right)$ defined by

$\operatorname{Sust}_{\beta}\left(A, U_{b}, B_{b}\right)=\left\{(x(0), y(0)) \mid \mathbb{P}_{\omega(.)}(x(t)\right.$ satisfies $\left.(7),(5),(10), t=0,1, \ldots, T) \geq \beta\right\}$.

\subsection{Protection effects}

A protection effect should capture processes through which both the conservation and catch services are enhanced by the existence of a reserve. First, we

3 The case where the confident rate is $\beta=100 \%$ is especially informative regarding sustainability. Hence, an intergenerational feature is directly induced by the invariance kernel Sust because the required constraints has to be satisfied in the same way at each generation. It could be depicted in terms of a maximin utility performance in a form closed to Rawls' criteria. In addition, the invariance kernel captures the irreversibility mechanism of a catastrophic scenario. Indeed, the very definition of this kernel implies that, for every state lying outside the sustainable kernel Sust, there exists a catastrophic uncertainty path leading to the violation of the conservation or production constraint. For instance, the extreme case where the sustainable kernel is empty corresponds to a totally non viable exploited ecosystem. 
introduce a co-viability effect which aims at measuring how the reserve reconciles conservation and utility goals. Second, a direct-use effect denoted by PAC (Protected Area for Catches) puts forward catches although maintaining conservation at a satisfying level.

Co-viability effect: Given the previous invariance and sustainability tools, we provide a formal definition of the co-viability effect. A mixed (or coviability) protected area effect at ecosystem state occurs if there exists a protected area size such that state is viable for this fishing size but not without MPA. In mathematical terms, this means that there exists a fishing size $A<1$ such that the state $(x, y)$ belongs to the sustainability kernel associated with this size $\operatorname{Sust}_{\beta}\left(A, U_{\mathrm{b}}, B_{\mathrm{b}}\right)$ but is not an element of the sustainability kernel $\operatorname{Sust}_{\beta}\left(1, U_{\mathrm{b}}, B_{\mathrm{b}}\right)$ with total opening $A=1$. Hence, a co-viability protected area effect holds at at state $(x, y)$ if

$$
\exists A \text { s.t. }(x, y) \in \operatorname{Sust}_{\beta}\left(A, U_{b}, B_{b}\right) \backslash \operatorname{Sust}_{\beta}\left(1, U_{b}, B_{b}\right) .
$$

Such a situation exhibits a co-viability performance since, with a partial reserve proportion $1-A$, the ecosystem performs better for both conservation $B_{\mathrm{b}}$ and catch dimensions $U_{\mathrm{b}}$.

Direct-use effect: The maximal guaranteed direct use value $U^{*}\left(A, x, y, B_{b}\right)$ defined as follows

$$
U^{*}\left(A, x, y, B_{b}\right)=\max \left(U_{b} \mid(x, y) \in \operatorname{Sust}_{\beta}\left(A, U_{b}, B_{b}\right)\right)
$$

is the maximal harvest utility than can be obtained while the ecosystem remains globally viable. The reserve size at state $(x, y)$ that is optimal with respect to catch corresponds to

$$
\mathrm{AC}^{*}\left(x, y, B_{b}\right)=\arg \max _{A \in[0,1]} U^{*}\left(A, x, y, B_{b}\right) .
$$

The protected area catch effect (PAC) index is derived from the difference between the maximal guaranteed direct use value $U^{*}\left(\mathrm{AC}^{*}\left(x, y, B_{b}\right), x, y\right)$ and the guaranteed direct use without protected area $U^{*}\left(1, x, y, B_{b}\right)$ :

$$
\operatorname{PAC}\left(x, y, B_{b}\right)=U^{*}\left(\mathrm{AC}^{*}\left(x, y, B_{\mathrm{b}}\right), x, y, B_{\mathrm{b}}\right)-U^{*}\left(1, x, y, B_{\mathrm{b}}\right) .
$$

A strictly positive PAC index captures a case where an ecosystem with a reserve yields better catch-related value than without a reserve. 


\section{An example: the Aboré Reef reserve}

\subsection{The Aboré Reef reserve}

The Noumea lagoon, located in South-Western New Caledonia, South Pacific hosts a large coral reef ecosystem where several marine reserves were established in the 1980's in the view of protecting the coral reef ecosystem from damage due to fishing and other human activities. The Aboré Reef reserve is located on a $25 \mathrm{~km}$ long barrier reef representing an area of 15000 ha. Fishing was banned from the whole reef from 1990 to 1993, and allowed again on 2/3 of the reef from August 1993 for a fishing experiment in the perspective of adaptive management. This opening was monitored by the Natural Resource Department of the South Province and the marine biology laboratory (LERVEM) at the New Caledonia University from two surveys undertaken in 1993 and 1995 (Amand et al. , 2003). Right after the reserve opening in August 1993, the number of vessels and induced fish yield during the 2 weeks after the opening reached the levels previously observed for an entire year. Monitoring of fishing effort and catch rates showed that, in the open area, benefits from the 1990-1993 closure were dissipated within a few weeks. The whole reef was finally closed to fishing from August 1995.

A survey was conducted in July 1993 and July 1995, respectively right before the opening and before the final closure, to assess to which extent the fish community, was affected by the opening. Results of the study can be found in Ferraris et al. (2005). A total of 374 species were observed during the survey. The analysis of species diets yielded 7 clusters, each cluster forming a trophic group. In each group, the mean diet included several food items, and groups were named on the basis of their mean diet composition. Food types were categorized as nekton, macroinvertebrates, macroalgae, microinvertebrates, microalgae, zooplankton, other plankton, coral and detritus. The species assemblage of Aboré was dominated (in species number) by macrocarnivores $(30 \%)$, algae feeders $(20 \%)$, zooplankton feeders $(14.5 \%)$, microcarnivores $(13.5 \%)$ and piscivores (12\%). Coral feeders represented $7 \%$ of the fish community.

As in many coral reef ecosystems, corals serve as a refuge for mainly small fishes. In New Caledonia, cyclone events deeply alter coral reefs and therefore strongly affect fish communities. Although there is no universal agreement regarding the behavior of tropical cyclones in a context of climatic and atmospheric changes (IPCC, 2001), some researchers estimate the occurrence of tropical cyclones could increase by as much as 50-60 \% (NASA, 2001).

We focus on three main issues related to the Aboré reserve: 
- Is there a reserve effect namely a reserve size that performs better from both catch and conservation viewpoints?

- Given the anthropogenic pressure, what is the protected area policy effective at achieving such sustainability goals?

- How do cyclone and climate risks mitigate the previous assertions given that threatened coral provides less refuge for prey?

\subsection{Ecosystems dynamics}

Hereafter, the time unit is assumed to be the day namely $\Delta t=1$. Four trophic group density $\left(g \cdot m^{-2}\right)$ and coral cover (percent) are considered in order to characterize the ecosystem state:

- Piscivores $x_{1}(t)$ are predators of fish and often targeted by fishers. They are $77 \mathrm{~cm}$-long on average. Large groupers are representative species of the group.

- Macrocarnivores $x_{2}(t)$ feed on macroinvertebrates and a few fish species. With an average length of $38 \mathrm{~cm}$, small groupers are illustrative species of this trophic group.

- Herbivores $x_{3}(t)$ are represented by parrot fishes Scarus sp. with an average length of 24 to $39 \mathrm{~cm}$. Some are targeted by fishers.

- Other fishes (small) $x_{4}(t)$ include sedentary and territorial organisms, microcarnivores $(17 \mathrm{~cm})$, coral feeders $(16 \mathrm{~cm})$, zooplanktonophages $(13 \mathrm{~cm})$.

- Coral cover percentage is denoted as $y_{1}(t)$.

Trophodynamics of the ecosystem: The dynamics of the ecosystem relies on trophic interactions between groups. The diet composition $\mathrm{Stom}_{j}^{i}$ is the proportion of prey $j$ in the stomach of predator $i$ :

$$
\operatorname{Stom}_{j}^{i}=\frac{\text { biomass of prey } j}{\text { total biomass of preys in stomach of } i}
$$

As explained in last section 6 from Ferraris et al. (2005) and Table 1, the diet composition is evaluated to be

$$
\text { Stom }=\left(\begin{array}{cccc}
0.01 & 0.17 & 0.41 & 0.17 \\
0 . & 0.02 & 0.05 & 0.02 \\
0 . & 0 . & 0 . & 0 . \\
0 . & 0 . & 0 . & 0 .
\end{array}\right)
$$

where index 1 to 4 respectively correspond to piscivores, macrocarnivores, herbivores, and other small fish (see above group definition). The matrix Stom 
indicates that piscivores $x_{1}$ are predators of every other group but mostly of herbivores $x_{3}$ that are more abundant in the fish assemblage. Not surprisingly, carnivores $x_{2}$ eat a few fish while herbivores $x_{3}$ and other small fish $x_{4}$ are only preys. From the food web and matrix Stom, we derive the following Lotka-Volterra model:

$$
\begin{aligned}
x_{1}(t+1) & =x_{1}(t)\left(R_{1}+\alpha_{1}^{1}\left(y_{1}(t)\right)\left(E_{1}^{1}-1\right) x_{1}(t)+E_{2}^{1} \alpha_{2}^{1}\left(y_{1}(t)\right) x_{2}(t)+\cdots+E_{4}^{1} \alpha_{4}^{1}\left(y_{1}(t)\right) x_{4}(t)\right) \\
x_{2}(t+1)= & x_{2}(t)\left(R_{2}-\alpha_{2}^{1}\left(y_{1}(t)\right) x_{1}(t)+\alpha_{2}^{2}\left(y_{1}(t)\right)\left(E_{2}^{2}-1\right) x_{2}(t)+\cdots+E_{4}^{2} \alpha_{4}^{2}\left(y_{1}(t)\right) x_{4}(t)\right) \\
& \vdots \\
x_{4}(t+1)= & x_{4}(t)\left(R_{4}-\alpha_{4}^{1}\left(y_{1}(t)\right) x_{1}(t)-\alpha_{4}^{2}\left(y_{1}(t)\right) x_{2}(t)-\cdots+\alpha_{4}^{4}\left(y_{1}(t)\right)\left(E_{4}^{4}-1\right) x_{4}(t)\right) .
\end{aligned}
$$

where

- the intrinsic growth rate $R_{k}$ includes mortality and recruitment of each trophic group $k$ independent of interactions with other trophic groups,

- $\alpha_{j}^{i}\left(y_{1}\right) x_{i}$ is the proportion of prey $j$ captured by $x_{i}$ predators $i$ in one time unit. The predation intensity $\alpha$ depends on coral cover $y_{1}$ through a refuge effect:

$$
\alpha_{j}^{i}\left(y_{1}\right)=\gamma\left(y_{1}\right) \widehat{\alpha}_{j}^{i}=\exp \left(y_{1}^{\sharp}-y_{1}\right) \widehat{\alpha_{j}^{i}}
$$

where the refuge parameter $y_{1}^{\sharp}$ corresponds to the maximal coral cover defined later in (12) and $\widehat{\alpha}$ is derived from the stomachal matrix Stom. Details of the relation between diet composition Stom and matrix $\widehat{\alpha}$ are exposed in the Appendix 6.

- $E_{j}^{i}$ stands for the conversion factor of one unit of prey $j$ density into predator growth $i$. Details are also exposed in the last Section 6 .

The dynamics of the trophic groups $i=1, \ldots, 4$ is summarized in matrix form by

$$
x_{i}(t+1)=x_{i}(t)\left(R+\exp \left(y_{1}^{\sharp}-y_{1}(t)\right) S x(t)\right)_{i}
$$

where the interaction matrix $S$ reads

$$
S=\left(\begin{array}{cccc}
\widehat{\alpha}_{1}^{1} E_{1}^{1}-\widehat{\alpha}_{1}^{1} & \widehat{\alpha}_{2}^{1} E_{2}^{1} & \widehat{\alpha}_{3}^{1} E_{3}^{1} & \widehat{\alpha}_{4}^{1} E_{4}^{1} \\
-\widehat{\alpha}_{2}^{1} & \widehat{\alpha}_{2}^{2} E_{2}^{2}-\widehat{\alpha}_{2}^{2} & \widehat{\alpha}_{3}^{2} E_{3}^{2} & \widehat{\alpha}_{4}^{2} E_{4}^{2} \\
-\widehat{\alpha}_{3}^{1} & -\widehat{\alpha}_{3}^{2} & 0 & 0 \\
-\widehat{\alpha}_{4}^{1} & -\widehat{\alpha}_{4}^{2} & 0 & 0
\end{array}\right)=\left(\begin{array}{cccc}
-0.093 & 0.013 & 0.013 & 0.013 \\
-0.106 & -0.012 & 0.002 & 0.002 \\
-0.076 & -0.01 & 0 . & 0 . \\
-0.53 & -0.069 & 0 . & 0 .
\end{array}\right)
$$


and the intrinsic productivity $R$ corresponds to

$$
R=\left(\begin{array}{l}
0.975 \\
1.007 \\
1.008 \\
1.054
\end{array}\right)
$$

as explained also in Appendix (section 6).

Habitat dynamics: Models of coral populations have shown that damage and recovery patterns of coral populations can be influenced by the characteristics of the disturbance regime (e.g. intensity, duration, frequency, timing), the characteristics of the affected coral species (e.g. growth rates, regeneration capabilities, reproductive mode), and the connectivity of affected populations. For instance, a detailed model of coral dynamics impacted by storm shocks can be find in Lirman (2003) through a transition matrix where it is shown how storm frequency affects the viability and resilience of coral. A simulation model of Andres \& Rodenhouse (1993) also focuses on the resilience of coral to hurricanes. Langmead \& Sheppard (2004) mimics patch disturbances and analyse their impact on the community structure of Caribbean corals using a cellular automata. In Mumby et al. (2006), the complex interactions between coral, herbivors, macroalgae and hurricanes events are examined through a spatially explicit simulation model. In the present paper, the coral dynamics is represented by a simple stochastic model with the aggregated coral cover as state variable. Such simplified dynamics for coral cover is characterized by four parameters: rate of destruction after storm, rate of recovery, maximal cover, frequency of cyclone which is uncertain as underlined previously. Referenced works and data provided in (Grigg \& Maragos, 1974; Dollar \& Tribble, 1993; Walsh, 1983; Harmelin-Vivien \& Laboute, 1986) are used to calibrate these parameters although they turn out to be very uncertain, controversial and context depending.

Coral evolution over time is described through the equation:

$$
y_{1}(t+1)=y_{1}(t) \cdot \begin{cases}R_{\text {cor }}\left(1-\frac{y_{1}(t)}{K_{\text {cor }}}\right) & \text { with probability }(1-p) \\ 0.3 & \text { with probability } p\end{cases}
$$

where

- $p$ is the probability of a cyclonic event. In the model, cyclonic events occur randomly with probability $p$ at each time step. In New-Caledonia, a cyclone 
happens on average every 5 to 6 years and setting $p=1 /(6 * 365)$ means that the cyclonic situation remains unchanged. We assume that the climatic change scenario corresponds to a rise of $50 \%$ in $p$ namely $p=1 /(4 * 365)$.

- Destruction rate of $70 \%$ is a rough approximation of severe reductions described in Walsh (1983) for Hawai or Harmelin-Vivien \& Laboute (1986) for French Polynesia. It is also in accordance with a study in Hawai detailled in Dollar \& Tribble (1993).

- $R_{\text {cor }}$ is the intrinsic productivity at low cover levels. After a cyclonic event, it is assumed that the coral grows by $10 \%$ a year but not linearly: it takes 8 to 10 years to reach the initial cover. Although this recovery process seems to be very uncertain, this scale of decade is in accordance with reports of Dollar \& Tribble (1993) or Grigg \& Maragos (1974) for limited reef damages. Simulations show that $R_{\text {cor }}=1.002$ for $\Delta t=1$ day is a plausible value in this respect.

- $K_{\text {cor }}$ is related to the so called carrying capacity $y_{1}^{\star}$ solution of

$$
1=R_{\mathrm{cor}}\left(1-\frac{y_{1}^{\star}}{K_{\mathrm{cor}}}\right)
$$

Observations in Aboré combined with data in Polynesia (Harmelin-Vivien \& Laboute, 1986) which indicate a maximal cover of $75 \%$ suggest to approximate the maximal value of $80 \%$ with the carrying capacity

$$
y_{1}^{\sharp}=\frac{R_{\mathrm{cor}}-1}{R_{\mathrm{cor}}} K_{\mathrm{cor}}=0.8 \text {. }
$$

Note that this coral dynamics does not account for decrease in coral cover due to coral feeders such as parrot fish. Such complex interactions with fishes are exhibited in Mumby et al. (2006).

Empirical estimates of abundances and densities: In 1995, the observed mean abundances of trophic groups 1 to 4 were

$$
x^{\star}=\left(\begin{array}{llll}
0.04 & 0.48 & 1.17 & 0.49
\end{array}\right) \mathrm{ind} / \mathrm{m}^{2}
$$

In the following, we assume that these values represent densities at equilibrium and also set the initial conditions to these equilibrium values ${ }^{4}$

$$
x(0)=x^{\star}=\left(\begin{array}{llll}
0.04 & 0.48 & 1.17 & 0.49
\end{array}\right) .
$$

\footnotetext{
${ }^{4}$ We must confess that such equilibrium assumption is an unsatisfying shortcut, given the importance of uncertainties in marine ecosystems and in particular in this specific coral reef. However it is convenient in terms of computation and based on the fact that the values are obtained in a protected area with reduced anthropogenic disturbances.
} 
We also set the initial habitat state $y_{1}(0)$ at equilibrium in the sense that

$$
y(0)=y_{1}^{\star}=0.8
$$

The Figure 1 displays trajectories over $T=30$ years of trophic groups $x_{i}(t)$ and coral densities $y_{1}(t)$ with no fishing $e(t)=0$. They depend on the probability $p$ of cyclonic event which takes three values. In recent years, the probability is set to $p=\frac{1}{6 * 365}$ which corresponds to a frequency of one cyclone every six years. The occurrence of a cyclone induces large oscillations of both coral density $y(t)$ and trophic group densities $x(t)$ in relation with the refuge effect. Hence climatic fluctuations related to cyclonic events result in a loss of coral cover leading to increased trophic interactions that mostly alter preys while the density of top predators like piscivore is enhanced. At later stages, predator-prey interactions are stabilized as coral recovers by growing, and a more balanced situation establishes until a new cyclone occurs. Our global change scenario inspired from (NASA, 2001) postulates a strong rise of $50-60 \%$ in cyclonic occurences. Thus the probability is assumed to be $p=\frac{1}{4 * 365}$ in this configuration. In this case, the coral generally lies at lower levels than in the previous case which penalizes preys (in particular $x_{4}$ ) as expected from refuge mechanisms. Hence, although the dynamics and state are modified, the ecosystem does not collapse in this global change scenario.

Exploited dynamics: For the area under study, fishing is basically recreational and associated mainly with spear gun technology. It is assumed to only affects piscivores $x_{1}(t)$, carnivores $x_{2}(t)$ and (large) herbivores $x_{3}(t)$. Consequently $c_{4}=0$. Assuming a simple Gordon Schaefer production function where $e(t)$ is the fishing effort, we write

$$
c_{i}(t)=q_{i} e(t) x_{i}(t)
$$

with zero catchability $q_{4}=0$. Unfortunately, quantitative informations on catches and effort in the area is not available. To overcome this difficulty, we impose some simplifications hereafter. We first assume that the effort rate in the overall area is targeted at some fixed level $e$. We further assume that catchability are equal for each fished group in the sense

$$
q_{1}=q_{2}=q_{3}
$$

However we do not specify $e$ and we study the results for a range $e \in[0,1]$. 


\subsection{The viability constraints}

A direct use value: We assume that the ecosystem provides direct uses through harvests of predators $x_{1}$ and $x_{2}$ and herbivores $x_{3}$. Catch in numbers is defined by $c_{i}(t)=q_{i} e x_{i}(t)$ and direct use $U$ is assumed to take the form of total catch in weight ${ }^{5}$ :

$$
U\left(c_{1}, c_{2}, c_{3}\right)=w_{1} c_{1}+w_{2} c_{2}+w_{3} c_{3}
$$

where $w_{i}$ stands for mean weight of group $i$. Weight values for each group are given by:

$$
W=\left(\begin{array}{llll}
0.5 & 0.5 & 0.7 & 0.1
\end{array}\right) \quad \mathrm{kg} \quad .
$$

The direct use constraint reads

$$
U\left(c_{1}(t), c_{2}(t), c_{3}(t)\right) \geq U^{b}
$$

where $U^{b}>0$ stands for some guaranteed satisfaction level.

A stronger conservation constraint: We adopt a stronger conservation point of view and introduce a biodiversity constraint in the sense that a trophic richness is guaranteed at a level $B_{b}$

$$
B(x(t))=\sum_{i} \mathbf{1}_{R_{*}^{+}}\left(x_{i}(t)\right) \geq B_{b} .
$$

This guaranteed trophic threshold $B_{b}$ which takes its values in $\{1,2,3,4\}$ ensures a minimal number of not exhausted groups.

\subsection{Results}

Hereafter, we adopt a very robust viability perspective since we present the case of greatest confident rate $\beta=100 \%$. The time horizon is set to $T=$ 30 years while initial time corresponds to year 1993 for projections. In this context, the results are based on simulations using the free scientific software SCILAB $^{6}$. We distinguish three cases depending on cyclone probability $p$. The first case is rather theoretical since no cyclone occurs which induces a constant

\footnotetext{
${ }^{5}$ In terms of recreational fishing, we must confess that recreational fishing is rather valued through the number of recreational trips and the size of the fish caught rather than total biomass as we do in the model. However, given that reserves tend to generate longer-lived and larger fish, we postulate that catch as a metric of value will likely understate the payoffs of a MPA.

6 http://www.scilab.org
} 
coral covering. The second case relies on current estimation of cyclonic event. The third case examines a climatic change context through a rise in cyclonic events.

The co-viability analysis without habitat changes: First it is assumed that no cyclonic shock affects coral, i.e. that $p=0$. We compute the effectiveness index PAC (11) presented in section 3 which measures the gain in catch resulting from the establishment of a reserve. Figure 2 shows PAC index computed for a range of effort values $e$ and guaranteed biodiversity $B_{b}$ values. It turns out that PAC is positive at exploitation rates $e$ between $10 \%$ and $30 \%$. The index can be strictly negative for high biodiversity requirement $B_{b}=4$ and high effort rate $e$ illustrating the fact that viability is not possible in this too demanding case. Figures 3 a) and b) represents state paths for two distinct reserve sizes. Piscivores $x_{1}(t)$ are in black color, carnivores $x_{2}(t)$ in dark blue, herbivores $x_{3}(t)$ in green, small preys $x_{4}(t)$ in blue lagoon color while coral state $y(t)$ is in red. In Figure $3(\mathrm{a})$, without reserve $(A=100 \%)$, carnivores and herbivores collapse. In Figure $3(\mathrm{~b})$, the maximal reserve size (here $A=\mathrm{AC}=50 \%$ ) provides guaranteed utility of captures larger than without protected area. It is achieved mainly from both carnivores and piscivores while herbivores are depleted. Thus biodiversity through trophic richness is not completely enhanced by such a reserve.

The co-viability analysis with current habitat changes: We now assume that $p=1 /(6 * 365)$ which is a current estimation of cyclonic probability by day. Compared to the case of constant coral habitat, the catch reserve effect is reinforced. Results are displayed in Figures 4 and 5. The catch index $\mathrm{PAC}$ is significant for low positive exploitation rates $e$. The size of significant effect is larger than in the previous constant habitat case since it holds for $10 \% \leq e \leq 60 \%$. In this sense, cyclonic events favor the protected area effect at least for catches. In Figure 5(a), without reserve $(A=100 \%)$, carnivores and herbivores are depleted because of fishing while in Figure 5(b) the maximal reserve size $(A=\mathrm{AC}=20 \%)$ provides a guaranteed utility of captures resulting from every targeted trophic group including carnivores, piscivores and herbivores. In this sense, the catch effect also favors biodiversity. Thus, in this case, catch reserve effects are compatible with biodiversity performance. 
The co-viability analysis with climatic changes: We now assume that $p=1 /(4 * 365)$ and the number of cyclonic events is $50 \%$ higher than in the current scenario. Such a change in cyclonic frequency may be roughly associated with a climatic change scenario although there is no general agreement regarding this concern. In Figures 7 (a) and (b), let us note that coral state $y(t)$ is more affected by this scenario as expected: coral never recovers its maximal cover $80 \%$ as before. However, catch reserve effect still holds true as depicted by Figures 6 and 7. A catch reserve effect again occur for the moderate harvesting effort $e=20 \%$. In Figure 7(a), without reserve $(A=100 \%)$, carnivores and herbivores are still overexploited. In Figure $7(\mathrm{~b})$, the maximal reserve size $(A=\mathrm{AC}=20 \%)$ provides guaranteed utility of harvests resulting from catches of every captured trophic group. Therefore, previous qualitative results persist despite this more agitated habitat. This puts forward the robustness of the MPA effects in terms of viability. This last statement reinforces the interest of protected area for the sustainability of the exploited ecosystem.

\section{Conclusion}

The present paper deals with the influence of protected areas upon fisheries sustainability within an eco-systemic framework. First, in a general setting, a spatially implicit dynamic bio-economic model is proposed integrating a trophic web, habitat dynamics, catches and environmental uncertainties. The performance of the exploited ecosystem is designed in terms of co-viability through the respect along time of constraints of both conservation and guaranteed captures. Using the mathematical concept of invariance kernel in a stochastic context, different MPA effects are introduced according to biodiversity and/or catches points of view. Finally, numerical simulations inspired from data of Aboré coral reef reserve in New Caledonia illustrate the main concepts.

The present paper is innovative in the methodological sense since invariance and viability modeling approaches are here used for sustainability issues and assessment of reserve effects. Such a framework extends equilibrium approach to uncertainty contexts and avoids important disadvantages of usual intertemporal optimality. Within this approach, the role of constraints are emphasized including conservation and exploitation requirements. Expanding population viability analysis ideas, the multi-criteria perspective of such an approach is worth to be pointed out for integrated modeling aiming at reconciling conservation and catch issues. Another advantage of the approach is to promote the intergenerational equity, one major component of sustainability.

The illustration on the Aboré reserve, based on real data, sheds interesting lights on the sustainable management of the exploited coral reef ecosystem. 
The model accounts for multi-trophic groups, harvest and habitat interactions. The dynamics of coral depends on climatic dimensions through cyclonic damages which may evolve with global changes. It turns out that MPA conservation objectives are not necessarily conflicting with MPA catches effect. However it is shown that a co-viability management through a protected area requires medium exploitation rate. Consequently reserve is not enough from the viability catches viewpoint: Regulation of the effort is also needed. This suggests a size of reopening for the area under concern coordinated with a control on fishing effort. Moreover, the climatic changes represented by rise in cyclonic shocks reinforce these assertions. Such an insight underlines resilience effects of MPA as pointed out in Grafton et al. (2005b).

Perspectives are numerous: One is to develop a spatially explicit model through a meta-population dynamics coping both with species and coral. Moreover, taking into account for at least two age classes for fish would allow to refine the model in a satisfying way for migration processes although this development may appear critic from the data viewpoint. The inclusion of more sophisticated catches agents behaviors is another exciting extension together with the integration of more realistic climatic scenarii. The monetary assessment of resource and biodiversity services through tourism is also a challenging task. 


\section{Appendix}

Diet composition: From Table 1 obtained in Ferraris et al. (2005), the diet composition is evaluated ${ }^{7}$ to be

$$
\text { Stom }=\left(\begin{array}{cccc}
0.01 & 0.17 & 0.41 & 0.17 \\
0 . & 0.02 & 0.05 & 0.02 \\
0 . & 0 . & 0 . & 0 . \\
0 . & 0 . & 0 . & 0 .
\end{array}\right)
$$

Identification of $\widehat{\alpha}$ : Consider the stomachal capacity $B_{k}$ as the maximum biomass that the stomach of the organism $k$ can contain: we suppose that it represents $30 \%$ of the organism mass. Consider the average mass $W_{k}$ of the organism $k$ supposed to be given by

$$
W=\left(\begin{array}{llll}
0.5 & 0.5 & 0.7 & 0.1
\end{array}\right) \quad \mathrm{kg}
$$

with typical species big grouper, small grouper, parrot fish, damsel fish.

Suppose that the densities $x_{j}^{\star}$ are at equilibrium. During a "stomachal cycle", we have

(1) $\operatorname{Stom}_{j}^{i}$ : proportion of biomass of prey $j$ in the stomach of predator $i$.

(2) $\operatorname{Stom}_{j}^{i} \times B_{i}$ : biomass of prey $j$ in the stomach of predator $i$.

(3) $\operatorname{Stom}_{j}^{i} \times B_{i} \times x_{i}^{\star}$ : biomass of preys $j$ in $x_{i}^{\star}$ stomachs of predator $i$.

Moreover, during a time unit, we have

7 The above matrix is the fruit of different assumptions:

- piscivores' diet is composed of $77 \%$ fish, of all species, especially small ones, with canibalism

- macrocarnivores' diet is composed of $10 \%$ fish, the rest being mostly invertebrates

- the proportions of diet composition by group is supposed to be the ambient proportions (perfect mixing and "opportunistic" behaviour assumptions)

- the predators eat other organisms like invertebrates, zooplankton, algae, etc.

- macrocarnivores eat mostly invertebrates

- herbivores eat mostly algae

- other fishes (small) eat mostly zooplankton or coral 
(1) $\widehat{\alpha}_{j}^{i} x_{j}^{\star} x_{i}^{\star}$ : number of preys $j$ caught by $x_{i}^{\star}$ predators $i$;

(2) $\widehat{\alpha}_{j}^{i} x_{j}^{\star} x_{i}^{\star} \times W_{j}$ : biomass of preys $j$ in $x_{i}^{\star}$ stomachs of predator $i$.

Therefore, if the time unit coincides with one "stomachal cycle":

$$
\operatorname{Stom}_{j}^{i} B_{i} x_{i}^{\star}=\widehat{\alpha}_{j}^{i} x_{j}^{\star} x_{i}^{\star} W_{j} \Longleftrightarrow \widehat{\alpha}_{j}^{i}=\frac{1}{x_{j}^{\star}} \frac{\operatorname{Stom}_{j}^{i} B_{i}}{W_{j}}
$$

Therefore, we obtain the matrix :

$$
\widehat{\alpha}=\left(\begin{array}{cccc}
0.106 & 0.106 & 0.076 & 0.53 \\
0 . & 0.014 & 0.01 & 0.069 \\
0 . & 0 . & 0 . & 0 . \\
0 . & 0 . & 0 . & 0 .
\end{array}\right)
$$

Identification of conversion factors $E_{j}^{i}$ :

$$
E_{j}^{i}=\frac{\text { number of individuals } i \text { produced }}{\text { number of individuals } j \text { consumed }} .
$$

The literature indicates that

$$
\widetilde{E}_{j}^{i}=\frac{\text { biomass } i \text { produced }}{\text { biomass } j \text { consumed }}
$$

have values of 0.12 for piscivores and 0.13 for macrocarnivores, whatever the prey. Thus we set

$$
\widetilde{E}_{j}^{i}=0.125, \quad j=1,2, i=1, \ldots, 4,
$$

and deduce that

$$
E_{j}^{i}=\widetilde{E}_{j}^{i} \times \frac{W_{j}}{W_{i}} \approx 0.125 \frac{W_{j}}{W_{i}}=\left(\begin{array}{cccc}
0.125 & 0.125 & 0.175 & 0.025 \\
0 . & 0.125 & 0.175 & 0.025 \\
0 . & 0 . & 0 . & 0 . \\
0 . & 0 . & 0 . & 0 .
\end{array}\right)
$$




\section{Identification of $S$ :}

$$
S=\left(\begin{array}{cccc}
\widehat{\alpha}_{1}^{1} E_{1}^{1}-\widehat{\alpha}_{1}^{1} & \widehat{\alpha}_{2}^{1} E_{2}^{1} & \widehat{\alpha}_{3}^{1} E_{3}^{1} & \widehat{\alpha}_{4}^{1} E_{4}^{1} \\
-\widehat{\alpha}_{2}^{1} & \widehat{\alpha}_{2}^{2} E_{2}^{2}-\widehat{\alpha}_{2}^{2} & \widehat{\alpha}_{3}^{2} E_{3}^{2} & \widehat{\alpha}_{4}^{2} E_{4}^{2} \\
-\widehat{\alpha}_{3}^{1} & -\widehat{\alpha}_{3}^{2} & 0 & 0 \\
-\widehat{\alpha}_{4}^{1} & -\widehat{\alpha}_{4}^{2} & 0 & 0
\end{array}\right)=\left(\begin{array}{cccc}
-0.093 & 0.013 & 0.013 & 0.013 \\
-0.106 & -0.012 & 0.002 & 0.002 \\
-0.076 & -0.01 & 0 . & 0 . \\
-0.53 & -0.069 & 0 . & 0 .
\end{array}\right) .
$$

Identification of growth rates: By writing that the densities $x_{i}^{\star}$ are at equilibrium, we obtain the intrinsic growth rates

$$
R_{i}=1-\sum_{j=1}^{4} S_{i}^{j} x_{j}^{\star}, \quad i=1, \ldots, 4
$$

and $R=(0.975,1.007,1.008,1.054)^{\prime}$.

Acknowledgements. We are very grateful to Michel Kubilcki, René Galzin and Loïc Thibaud for all their hints on coral ecosystem functioning and for the essential data that they furnished for the Aboré reserve. Ines Bouzidi, Patrick Rabbat, Liu Dun and Jeremy Bourgoin have contributed in a very significant way to the development of the model. This work was supported by the Institut Français de la Biodiversité (IFB) through a research contract coping with "Biodiversity and Global Changes" issues.

\section{References}

Agardy, T., Bridgewater, P., Crosby, M. P., Day, J., Dayton, P. K., Kenchington, R., Laffoley, D., McConney, P., Murray, P. A., Parks, J. E., \& Peau, L. 2003. Dangerous targets? Unresolved issues and ideological clashes around marine protected areas. Aquatic Conservation: Marine and Freshwater Ecosystems, 13, 353-367.

Amand, M., Pelletier, D., Ferraris, J., \& Kulbicki, M. 2003. A step toward the definition of ecological indicators of the impact of fishing on the fish assemblage of the Abore reef reserve (New Caledonia). Aquatic Living Resource, 17, 139-149.

Andres, N. G., \& Rodenhouse, N. L. 1993. Resilience of corals to hurricanes : a simulation model. Coral Reefs, 12, 167-175.

Aubin, J.-P. 1991. Viability Theory. Boston: Birkhäuser. 
Beatie, A., Sumaila, U.R., Christensen, V., \& Pauly, D. 2002. A model for the bioeconomic evaluation of marine protected area size and placement in the north sea. Natural Resource Modeling, 15(4).

Bellwood, D. R., Hughes, T. P., Folke, C., \& Nystrom, M. 2004. Confronting the coral reef crisis. Nature, 429, 827-833.

Béné, C., \& Doyen, L. 2000. Storage and viability of a fishery with resource and market dephased seasonnalities. J. of Environmental Resource Economics, 15, $1-26$.

Béné, C., Doyen, L., \& Gabay, D. 2001. A viability analysis for a bio-economic model. Ecological Economics, 36, 385-396.

Boncoeur, J., Alban, F., Guyader, O., \& Thebaud, O. 2002. Fish, fishers, seals and tourists: economic consequences of creating a marine reserve in a multi-species, multi-activity context. Natural Resource Modeling, 15(4).

Bruckner, T., Petschell-Held, G., Toth, F.L., Fussel, H.M., Helm, C., Leimbach, M., \& Schellnhuber, H.J. 1999. Climate change decision-support and the tolerable windows approach. Environmental Modeling and Assessment, 4, 217-234.

Cesar, H. 2000. Collected Essays on the Economics of Coral Reefs. Tech. rept. Kalmar Sweden.

Charles, A. 2001. Sustainable Fishery Systems. Blackwell.

Clark, C. W. 1990. Mathematical Bioeconomics. second edn. New York: Wiley.

Clarke, F.H., Ledayev, YU. S., Stern, R.J., \& Wolenski, P.R. 1995. Qualitative properties of trajectories of control systems: a survey. Journal of Dynamical Control Systems, 1, 1-48.

Connell, J. H., Hughes, T. P., \& Wallace, C.C. 1997. A 30-year study of coral abundance, recruitment and disturbance at several scales in space and time. Ecological Monographs, 67, 461-488.

Conrad, J.M. 1999. Resource economics. Cambridge University Press.

Cury, P., Mullon, C., Garcia, S., \& Shannon, L. J. 2005. Viability theory for an ecosystem approach to fisheries. ICES Journal of Marine Science, 62(3), $577-584$.

DeLara, M., Doyen, L., Guilbaud, T., \& Rochet, M-J. 2007. Is a management framework based on spawning stock biomass indicator sustainable? A viability approach. ICES Journal of Marine Science, 64.

Dollar, S. J., \& Tribble, G. T. 1993. Recurrent storm disturbance and recovery: a long-term study of coral communities in Hawaii. Coral reefs, 12, 223-233.

Doyen, L., \& Bene, C. 2003. Sustainability of fisheries through marine reserves: a robust modeling analysis. J. of Environmental Management, 69, 1-13.

Eisenack, K., Sheffran, J., \& Kropp, J. 2006. The Viability Analysis of Management Frameworks for fisheries. Environmental modelling and assessment, 11(1), 69-79.

Ferraris, J., Pelletier, D., Kulbicki, M., \& Chauvet, C. 2005. Assessing the impact of removing reserve status on the Abore reef fish assemblage in New Caledonia. Mar Ecol Prog Ser, 292, 271-286.

Grafton, R., Kompas, T., \& Schneider, V. 2005a. The Bioeconomics of Marine 
Reserves: A Selected Review with Policy Implications. Journal of Bioeconomics, 7, 161-178.

Grafton, R.Q., Kompas, T., \& Lindenmayer, D. 2005b. Marine reserves with ecological uncertainty. Bulletin of Mathematical Biology, 67(5), 957-971.

Grigg, R., \& Maragos, J. 1974. Recolonization of hermatypic corals on submerged lava flows in Hawaii. Ecology, 55, 387-395.

Harmelin-Vivien, M.L., \& Laboute, P. 1986. Catastrophic impact of hurricanes on atoll outer reef slopes in the Tuamotu-French Polynesia. Coral Reefs, 5, $55-62$.

Heal, G. 1998. Valuing the Future, Economic Theory and Sustainability. New York: Columbia University Press.

Hilborn, R., Orensanz, J., \& Parma, A. 2005. Institutions, incentives and the future of fisheries. Phil. Trans. R. Soc. Lond. B, 360(1453), 47-57.

Hughes, T.P. et al. 2003. Climate Change, human impacts and the resilience of coral reefs. Science, 301, 929-933.

IPCC. 2001. Climate Change 2001: Impacts, Adaptation, and Vulnerability. Cambridge University Press.

Langmead, O., \& Sheppard, C.R.C. 2004. Coral reef community dynamics and disturbance: a simulation model. Ecol. Mod., 175, 271-290.

Lauck, T., Clark, C.W., Mangel, M., \& Munro, G.R. 1998. Implementing the Precautionary Principle in Fisheries Management through Marine Reserves. Ecological Applications, 81, Special Issue, S72-78.

Lirman, D. 2003. A simulation model of the population dynamics of the branching coral Acropora palmata. Effects of storm intensity and frequency. Ecological Modeling, 161, 169:182.

Martinet, V., \& Doyen, L. 2007. Sustainable management of an exhaustible resource: a viable control approach. Journal of Resource and Energy Economics, 29 (1), p.17-39.

Martinet, V., Thébaud, O., \& Doyen, L. in press. Defining viable recovery paths toward sustainable fisheries. Ecological Economics.

Morris, W.F., \& Doak, D. F. 2003. Quantitative Conservation Biology: Theory and Practice of Population Viability Analysis. Sinauer Associates.

Mumby, P.J., Hedley, J.D., Zychaluk, K., Harborne, A.R., \& Blackwel, l P.G. 2006. The spatial ecology of Caribbean coral reefs: revisiting the catastrophic die-off of the urchin Diadema antillarum. Ecological Modelling, 196 (1-2), 131-148.

NASA. 2001. How will the frequency of hurricanes be affected by climatic changes? Tech. rept. NASA Goddard Institute for Space Studies.

Pandolfi, J.M. et al. 2003. Global trajectories of the long-term decline of coral reef ecosystems. Science, 301, 955-958.

Pelletier, D., \& Mahévas, S. 2005. Spatially explicit fisheries simulation models for policy evaluation. Fish and Fisheries, 6, 307-349.

Pinnegar, J.K., Polunin, N. V. C., Francour, P., Badalamenti, F., Chemello, R., Harmelin-Vivien, M.L., Hereu, B., Milazzo, M., Zabala, M., D'Anna, G., \& Pipitone, C. 2000. Trophic cascades in benthic marine ecosystems : lessons 
for fisheries and protected-area management. Environmental Conservation, 27, 179-200.

Rapaport, A., Terreaux, J. P., \& Doyen, L. 2006. Sustainable management of renewable resource: a viability approach. Mathematics and Computer Modeling, 43, 466-484.

Russ, G.R. 2002. Yet another review of marine reserves as reef fisheries management tools. Chap. 19, pages 421-443 of: Sale, P.F. (ed), Coral Reef Fishes: Dynamics and Diversity in a Complex Ecosystem. San Diego: Academic Press.

Sanchirico, James N. 2005. Additivity properties in metapopulation models: implications for the assessment of marine reserves. Journal of Environmental Economics and Management, 49, 1- 25.

Sanchirico, J.E., \& Wilen, J.N. 2001. A Bioeconomic Model of Marine Reserve Creation. Journal of Environmental Economics and Management, 42, 257276.

Shin, Y.J. 2001. Simulation of the effects of marine protected areas on yield and diversity using a multispecies, spatially-explicit, individual-based model. Pages 627-642 of: Spatial processes and management of fish populations. G.H. Kruse, N. Bez, T. Booth and M. Dorn and S. Hills, R. Lipcius, D. Pelletier, C. Roy, S. Smith and W.S.

Smith, M.D., \& Wilen, J.E. 2003. Economic impacts of marine reserves: the importance of spatial behavior. Journal of Environmental Economics and Management, 46, 183-206.

Tichit, M., Doyen, L., Lemel, J.Y., \& Renault, O. in press. A co-viability model of grazing and bird community management in farmland. Ecological Modeling.

Walsh, W. J. 1983. Stability of a coral reef fish community following a catastrophic storm. Coral reefs, 2, 49-63. 


\begin{tabular}{|c|c|c|c|c|c|c|c|}
\hline & $\begin{array}{c}\text { Piscivores } \\
(\mathrm{Pi})\end{array}$ & $\begin{array}{c}\text { Macro } \\
\text { carnivores } \\
(\mathrm{MC})\end{array}$ & $\begin{array}{c}\text { Micro } \\
\text { carnivores } \\
(\mathrm{mC})\end{array}$ & $\begin{array}{c}\text { Coral } \\
\text { feeders } \\
(\mathrm{Co})\end{array}$ & $\begin{array}{l}\text { Herbivores } \\
\qquad(\mathrm{He})\end{array}$ & $\begin{array}{c}\text { Microalgae } \\
\text { Detritivores } \\
(\mathrm{mAD})\end{array}$ & $\begin{array}{c}\text { Zooplankton } \\
\text { feeders } \\
(\text { Zoo })\end{array}$ \\
\hline GROUP FOR THE MODEL & $X_{1}$ & $X_{2}$ & $X_{4}$ & $X_{4}$ & $X_{3}$ & $X_{3}$ & $X_{4}$ \\
\hline SPECIES RICHNESS & 46 & 112 & 50 & 26 & 10 & 73 & 54 \\
\hline \multicolumn{8}{|l|}{ DiET COMPOSITION (\%) } \\
\hline - Nekton & 77 & 10 & 2 & 0 & 0 & 0.1 & 1 \\
\hline - Macroinvertebrates & 21 & 82 & 20 & 2 & 0 & 2 & 1 \\
\hline - Microinvertebrates & 0.3 & 6 & 67 & 11 & 3 & 5 & 6 \\
\hline - Zooplankton & 1 & 0.4 & 3 & 2 & 0 & 3 & 79 \\
\hline - Other plankton & 0 & 0 & 0 & 0 & 0 & 0 & 0.3 \\
\hline - Macroalgae & 0 & 0.3 & 1 & 0 & 66 & 3 & 0.3 \\
\hline - Microalgae & 0 & 1 & 5 & 7 & 28 & 80 & 11 \\
\hline - Coral & 0 & 0.3 & 2 & 77 & 0 & 1 & 0.3 \\
\hline - Detritus & 0 & 0.3 & 1 & 1 & 4 & 6 & 0.2 \\
\hline MAXimum ADULt SIZE (CM) & 77 & 38 & 17 & 16 & 39 & 24 & 13 \\
\hline
\end{tabular}

Table 1

Species richness, mean diet composition and adult size 


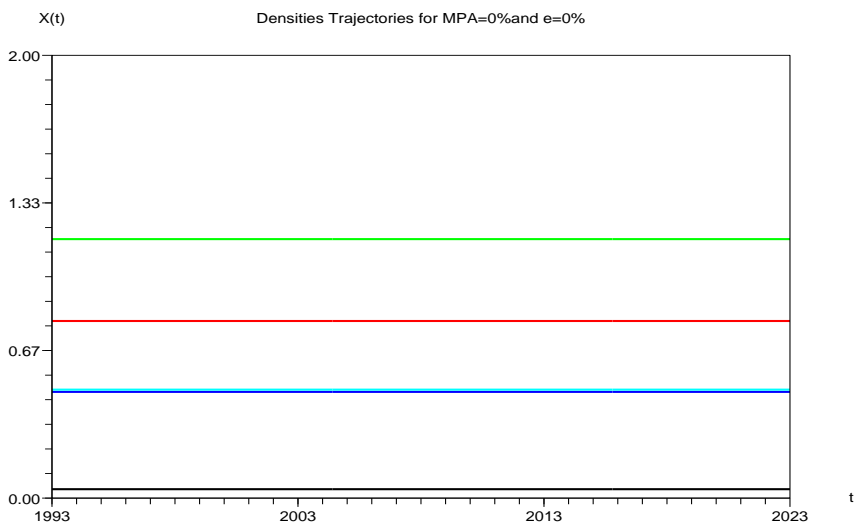

(a) Zero cyclonic probability $p=0$

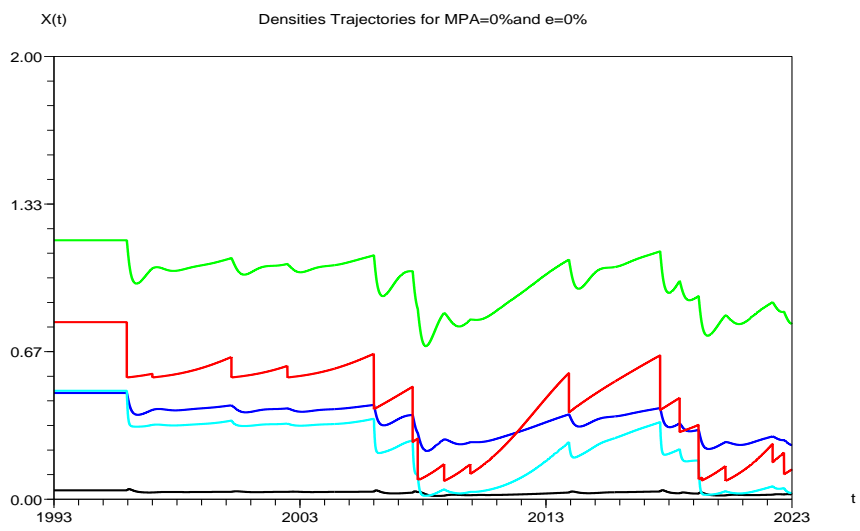

(b) Current cyclonic probability $p=\frac{1}{6 * 365}$

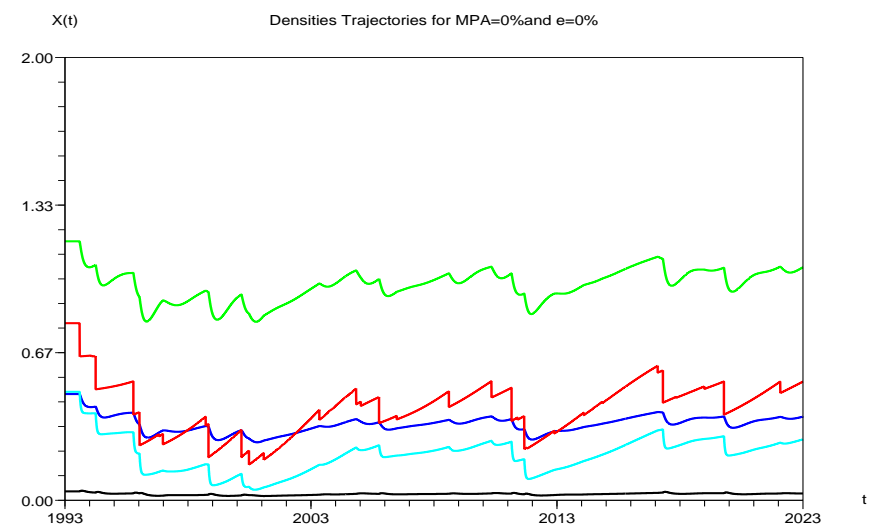

(c) High Cyclonic probability $p=\frac{1}{4 * 365}$

Fig. 1. Projections of ecosystem trajectory $(x(t), y(t))$ over $T=30$ years starting from 1993 with no fishing $e(t)=0$, and for several probabilities $p$ of cyclonic events : a) no cyclone ; b) a cyclone every 6 years; c) a cyclone every 4 years. Piscivores $x_{1}(t)$ are in black color, carnivores $x_{2}(t)$ in dark blue, herbivores $x_{3}(t)$ in green, small preys $x_{4}(t)$ in blue lagoon color while coral state $y(t)$ is in red. 


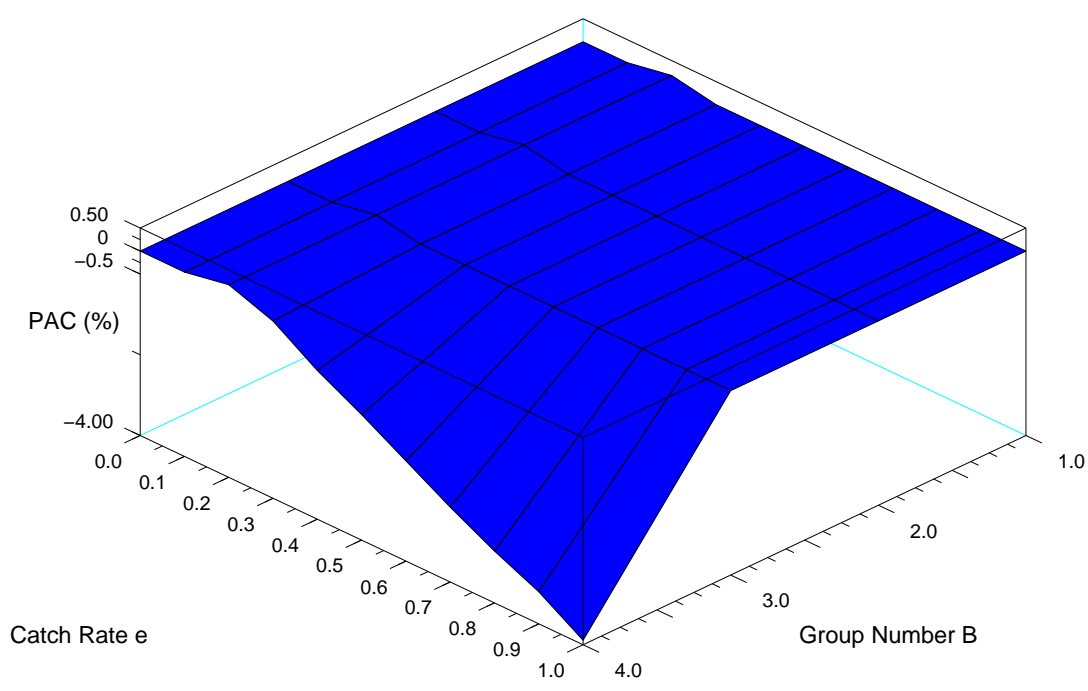

Fig. 2. The case of no cyclonic event $p=0$. The catch Reserve Effect index PAC with respect to guaranteed trophic richness $B \in\{1, \ldots, 4\}$ and catch rate $e \in[0,1]$. Index PAC is significant $(>0)$ for low exploitation rate $10 \%<e<30 \%$. PAC can be strictly negative for high biodiversity requirement $B=4$ and high effort rate $e$ indicating that viability is not possible in this too demanding case.

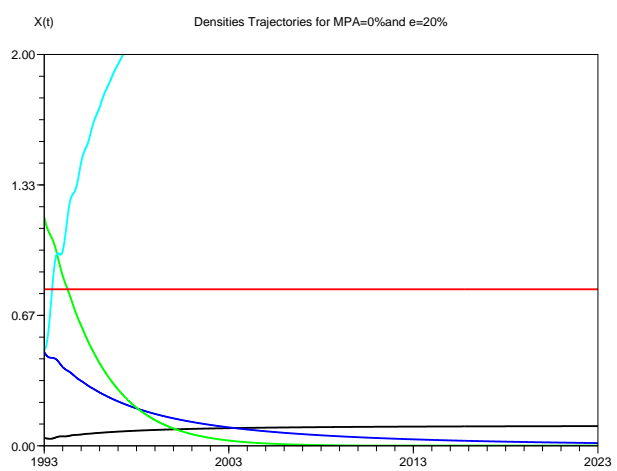

(a) Without reserve $\mathrm{MPA}=0 \%$

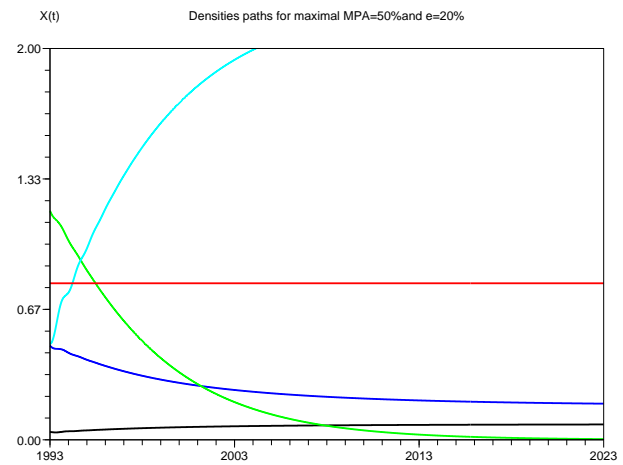

(b) Optimal $\mathrm{MPA}=50 \%$

Fig. 3. Projections of state $(x(t), y(t))$ in the case of no cyclonic event $p=0$ for the harvesting effort $e=20 \%$. In (a), without reserve $A=100 \%$, carnivores and herbivores collapse due to fishing, thus reducing the guaranteed captures. While in (b), the maximal reserve size $A=50 \%$ generates a reserve effect more in favor of catches than biodiversity: The guaranteed utility of captures turns out to be larger than without protected area. However it is achieved mainly from both carnivores and piscivores while herbivores still remain depleted. 


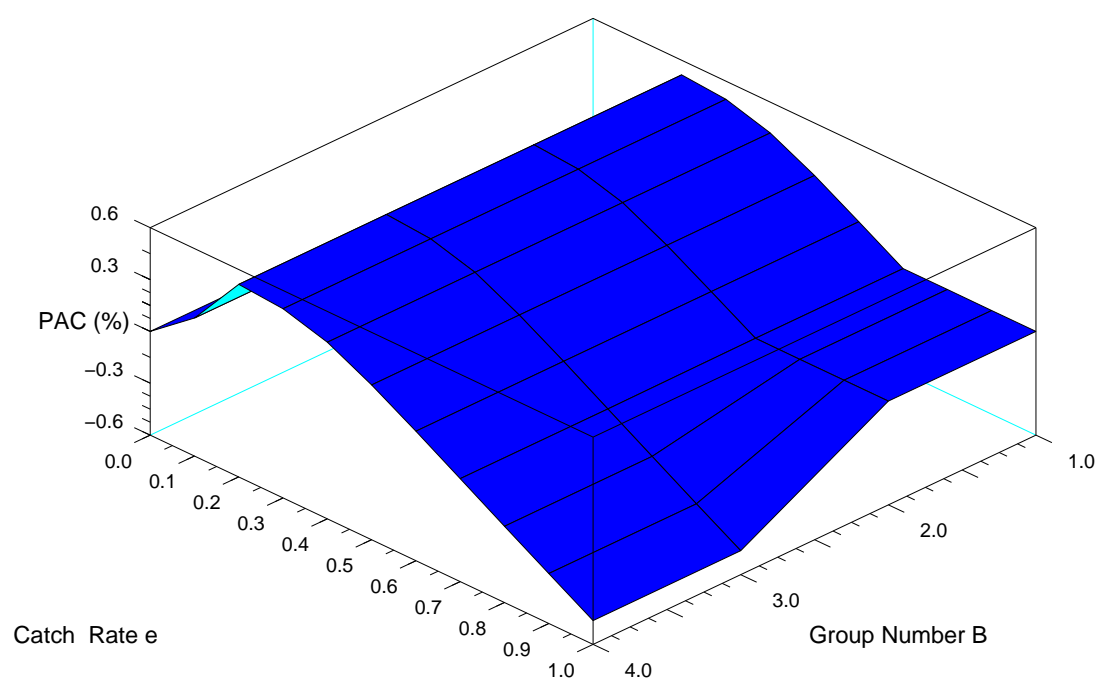

Fig. 4 . The case of current cyclonic probability $p=1 /(6 * 365)$ which means a cyclone every six years. The catch Reserve Effect index PAC with respect to guaranteed trophic richness $B \in\{1, \ldots, 4\}$ and catch rate $e \in[0,1]$. The catch indexes PAC is significant for low exploitation $10 \% \leq e \leq 60 \%$.

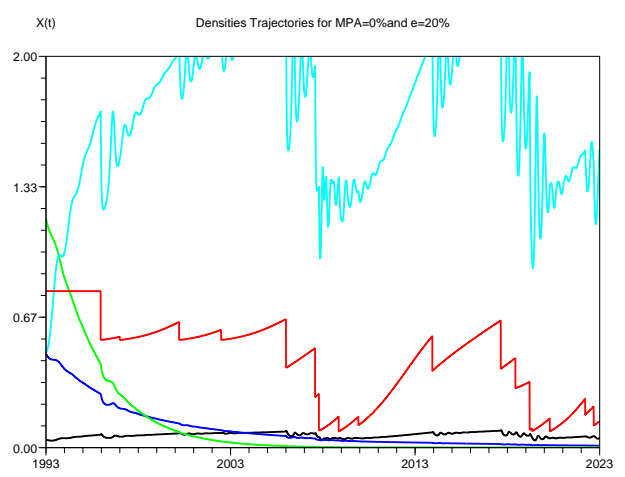

(a) Without reserve $\mathrm{MPA}=0 \%$

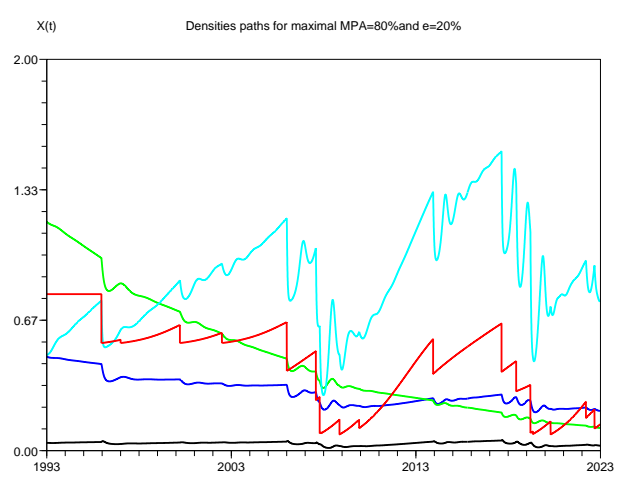

(b) Optimal $\mathrm{MPA}=80 \%$

Fig. 5. Projections of state $(x(t), y(t))$ in the case of current cyclonic frequency $p=1 /(6 * 365)$ for the moderate fishing effort $e=20 \%$. In (a) without reserve, i.e. $A=100 \%$, no guaranteed captures of carnivores is achieved while in (b) under the maximal reserve size $A=A C=20 \%$ guaranteed utility of catch resulting from all trophic groups is exhibited. 


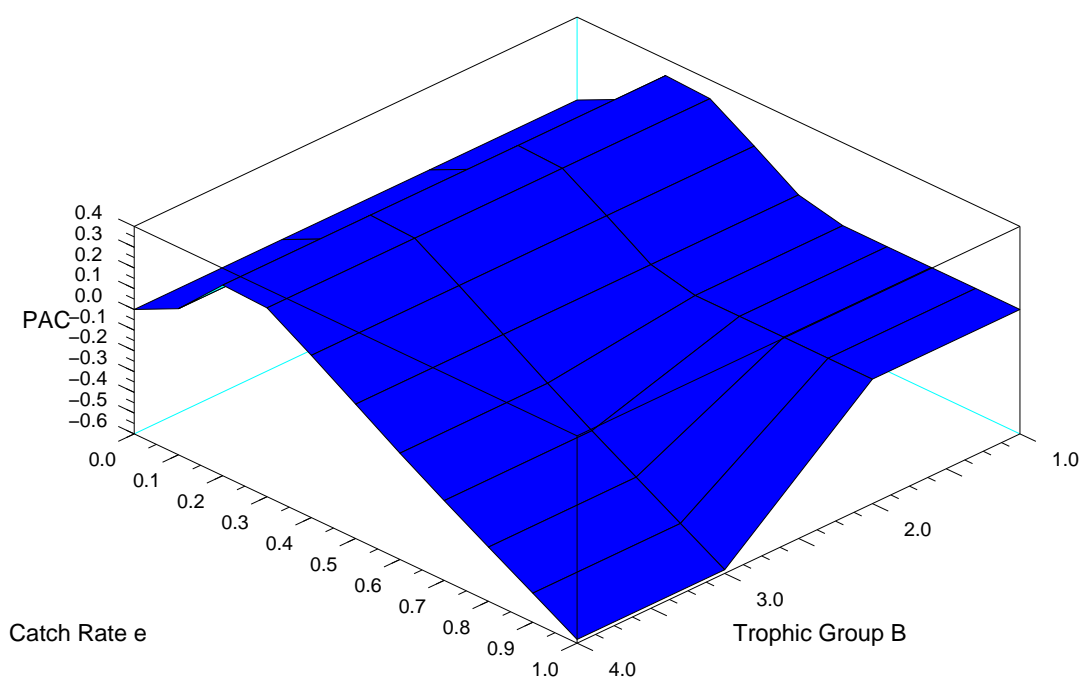

Fig. 6. Cyclone events rise $p=1 / 4 * 365$. The catch Reserve Effect index PAC with respect to guaranteed trophic richness $B \in\{1, \ldots, 4\}$ and catch rate $e \in[0,1]$. Catch reserve effects occur for moderate efforts $10 \% \leq e \leq 60 \%$.

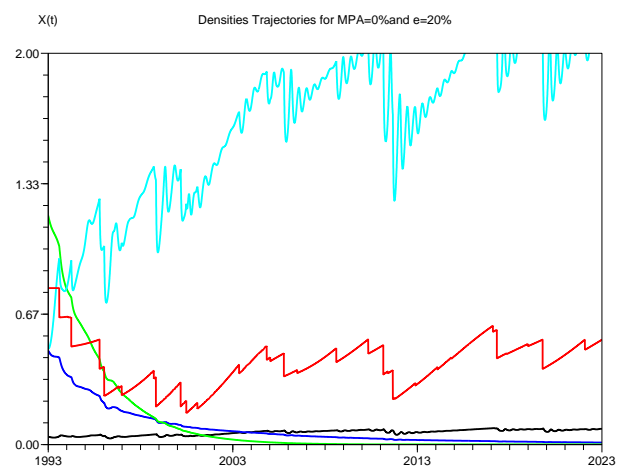

(a) Without reserve $\mathrm{MPA}=0 \%$

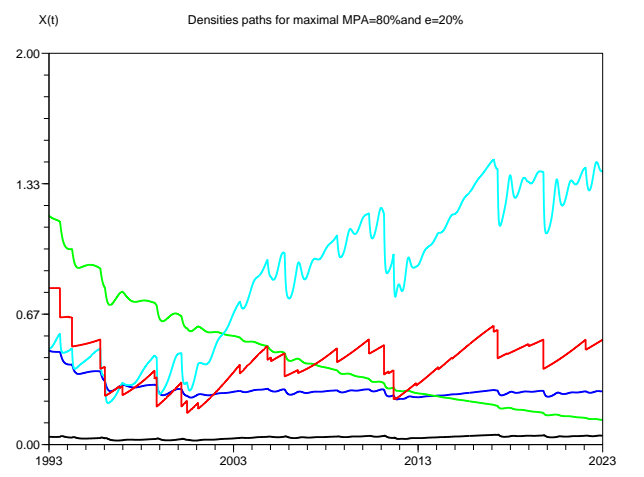

(b) Optimal MPA $=80 \%$

Fig. 7. Projections of state $(x(t), y(t))$ when cyclone events rise $p=1 /(4 * 365)$ for the harvesting effort $e=20 \%$. In Figure (a), without reserve $A=100 \%$, carnivores and herbivores are overexploited. In Figure (b) the maximal reserve size $A=20 \%$ provides guaranteed utility of harvests resulting from every captured trophic group. 